\title{
Propondo um Método de Avaliação de Processo de Software em Micro Empresas Incubadas
}

\author{
Kênia Karim Pickler ${ }^{1}$, Christiane Gresse von Wangenheim ${ }^{1}$, Clenio Figueiredo \\ Salviano $^{2}$ \\ ${ }^{1}$ Universidade do Vale do Itajaí (UNIVALI) - Centro de Educação São José \\ São José - SC - Brasil \\ ${ }^{2}$ Centro de Pesquisas Renato Archer (CenPRA)-Campinas - SP - Brasil \\ (kenia, gresse) @univali.br, clenio.salviano@cenpra.gov.br
}

\begin{abstract}
As part of the research project 15504MPE, a software process assessment method is being developed adapted to small Brazilian start-up companies based on the standard ISO/IEC 15504. The objective of the customization is to facilitate the application of the standard also in this kind of company aiming at the improvement of the software process improvement of the companies and to provide a basis for monitoring and orientation of incubators to their associated companies in an effective and efficient way. In this paper, we describe the method being developed. First experiences are also presented based on its application in one small start-up company associated to the incubator Centro GeNESS/Florianópolis.
\end{abstract}

Resumo. No contexto do projeto de pesquisa 15504MPE está sendo desenvolvido um método de avaliação de processo de software adaptado a empresas incubadas de software Brasileiras com base na norma ISO/IEC 15504. O objetivo desta adaptação é facilitar a aplicação da norma neste tipo de empresa visando à melhoria do processo de software das empresas recém formadas e prover uma base para o acompanhamento e orientação pela incubadora às empresas associadas numa forma efetiva e eficiente. Neste artigo, apresentamos o método que está sendo desenvolvido. Também são mostradas as primeiras experiências ganhas na aplicação do método em uma micro empresa associada à Incubadora Centro GeNESS/Florianópolis.

\section{Introdução}

Segundo pesquisas internacionais, o setor de software será responsável pelos maiores índices de crescimento da economia global nos próximos anos [MCT, 2001]. Essa situação favorável incentiva à criação constante de novos e pequenos empreendimentos ligados a esta área. Isto também é estimulado pelas incubadoras de empresas, que agem como grandes instrumentos de inovação em todo o mundo. Estas incubadoras são programas de assistência às micro e pequenas empresas (MPEs) em fase inicial. Sua finalidade é viabilizar projetos, criar novos produtos, processos ou serviços, gerar novas

O presente trabalho foi realizado com o apoio do CNPq, uma entidade do Governo Brasileiro voltada ao desenvolvimento científico e tecnológico. 


\section{Simpósio Brasileiro de Qualidade de Software}

empresas que, após deixarem a incubadora, estejam aptas a se manter no mercado. Geralmente, as incubadoras oferecem uma infra-estrutura de uso compartilhado, assistência, treinamento na área de negócios e acesso facilitado aos grupos de pesquisa e ao mercado. Neste contexto, no Brasil, se destacam as pré-incubadoras GENES SOFTEX [SOFTEX, 2004] que prestam apoio operacional às empresas de software, funcionando em diversas regiões do país. Estas entidades atuam em articulação com a iniciativa privada, governos estaduais ou municipais, instituições de desenvolvimento e universidades, para desta forma atingir os objetivos e metas do setor de software da SOFTEX. Cada GENE funciona independentemente e possui infra-estrutura computacional e um corpo de consultores, que assessoram os jovens empreendedores na tarefa de estruturação de seus empreendimentos.

Em geral, a experiência dessas iniciativas demonstra que o incentivo às incubadoras é uma fonte de desenvolvimento econômico e de inovação tecnológica. Porém, muitas empresas de software, e conseqüentemente as micro empresas associadas a incubadoras enfrentam problemas referentes à qualidade dos processos e aos produtos de software. Tipicamente, as micro empresas recém formadas apresentam uma deficiência organizacional e administrativa devido à informalidade de seus processos e à escassez de recursos. O principal objetivo destas empresas é geralmente a entrega do produto final para deste modo, garantir a sua sobrevivência no mercado. Além disto, existe uma necessidade de agilidade à adaptação das constantes mudanças do mercado, da tecnologia ou dos clientes. Como resultado, o processo de software tem uma deficiência freqüente no que se refere à qualidade, produtividade e previsibilidade prejudicando, desta forma, a competitividade e até mesmo a sobrevivência da empresa no mercado. Para a incubadora que geralmente acompanha as empresas associadas e oferece consultoria e treinamento, é importante ter um meio fácil e objetivo para acompanhar o progresso das empresas. Este acompanhamento auxilia no direcionamento das ações de melhoria e também ajuda a ter uma base para direcionar sistematicamente a consultoria e o treinamento de acordo com reais necessidades das empresas associadas.

Com este objetivo pode ser feita uma avaliação de processo de software nas empresas associadas visando à identificação de pontos fortes e fracos no seu processo. Existem vários modelos (como p.ex. o CMMI/CMM [SEI, 2004] ou mps-BR [MPS, 2005]) ou normas (p.ex., ISO 9000 [ABNT, 2001], ISO/IEC 15504 [ISO, 2003]) voltado para a avaliação de processo. Entretanto, atualmente não existem métodos especificamente voltados para o contexto de micro empresas recém formadas. Entre os modelos existentes, se destaca a norma ISO/IEC 15504, como um padrão reconhecido internacionalmente tanto para o objetivo de melhoria de processos quanto para determinação da capacidade. Baseado em um modelo bidimensional, a ISO/IEC 15504 se mostrou flexível e também adaptável ao contexto de micro e pequenas empresas [SPICE, 2005]. Entretanto, como a norma em si não fornece um método de avaliação, a aplicação da ISO/IEC 15504 neste tipo de empresa ainda requer esforço e conhecimento consideráveis, o que dificulta sua ampla utilização neste contexto. Por este motivo, estamos desenvolvendo um método de avaliação de processos adaptado ao contexto específico de micro empresas incubadas que suporta a realização de uma avaliação com dois objetivos: identificar as oportunidades de melhoria nas empresas e avaliar a capacidade dos processos das empresas provendo o suporte realizado pela incubadora 
para o acompanhamento destas empresas e o direcionamento da consultoria/treinamento.

\section{A Norma ISO/IEC 15504}

A ISO/IEC 15504 está sendo desenvolvida por meio de uma iniciativa da comunidade internacional, que a partir do projeto SPICE trabalhou no desenvolvimento de uma norma internacional para avaliação de processos. A norma é voltada para:

- Melhoria dos processos: gerando perfis de capacidade dos processos, identificando os pontos fracos e fortes, que serão utilizados para a elaboração de um plano de melhorias;

- Determinação da capacidade dos processos: viabilizando a avaliação de um fornecedor em potencial, obtendo o seu perfil de capacidade.

A norma é dividida em cinco partes, sendo que destas apenas a parte 2 é normativa. As partes 1,2, 3 e 4 já foram publicadas como um padrão internacional em 2003 e 2004. A parte 5 está atualmente em processo de padronização, estando disponível como relatório técnico. Para simplificação das referências, aqui nós especificamos esta discriminação das partes somente quando necessário.

A ISO/IEC 15504 define um modelo bidimensional que descreve os processos e os níveis de capacidade utilizados em um processo de avaliação (vide figura 1).

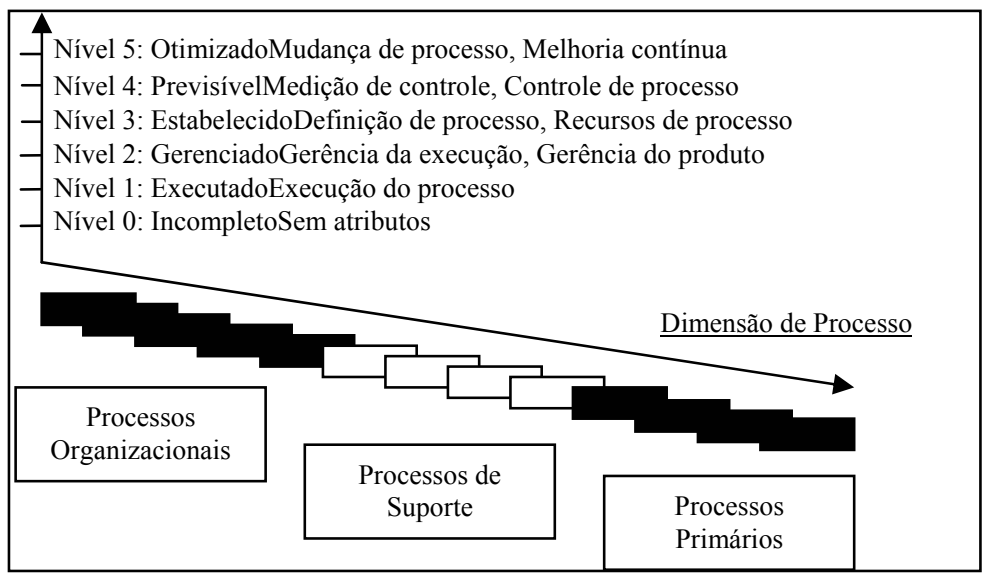

Figura 1: Dimensões da ISO/IEC 15504

- Dimensão de processo. A dimensão de processo é composta por um subconjunto de processos os quais são descritos em um modelo de referência de processo, que define um conjunto universal de processos de software. Atualmente, o modelo de referência de processo utilizado para o domínio de software é a ISO/IEC 12207 Amd. 1/2 [ISO, 2002]. O exemplo de modelo de avaliação apresentado na parte 5 da ISO/IEC 15504 utiliza esta norma como modelo de referência de processo, detalhando os processos do modelo para conter as práticas base e produtos de trabalho de entrada e saída que auxiliam na execução de cada processo para alcançar seus resultados esperados.

- Dimensão de capacidade. A dimensão de capacidade é definida em uma escala ordinal de seis pontos que varia do nível 0 - incompleto ao nível 5- otimizado como descrito na estrutura de medição na parte 2 da ISO/IEC15504. A norma fornece um esquema para a caracterização da capacidade de um processo de 
acordo com o Modelo de Avaliação de Processo baseado num conjunto de Atributos de Processo. Cada um dos Atributos de Processo define um aspecto particular da capacidade. A extensão da realização de um Atributo de Processo é caracterizada em uma escala de avaliação ordinal de quatro pontos, variando de $\mathrm{N}$ - não atingido a $\mathrm{F}$ ("Fully")- completamente atingido, e está sendo indicada por meio de um conjunto de indicadores associados a cada Atributo de Processo. No nível 1 de capacidade, estes indicadores são relacionados a dimensão de processo com o objetivo de atingir o propósito dos resultados do processo. Com respeito ao nível 2 a 5 de capacidade, os indicadores são relacionados às atividades, aos recursos ou aos resultados associados com a finalidade da realização do respectivo propósito do Atributo de Processo.

O resultado de uma avaliação consiste de um conjunto de Atributos de Processo para cada processo avaliado, denominado Perfil de Processos. Pode também incluir o nível de capacidade alcançado por um processo, que é determinado baseado na combinação da execução de Atributos de Processo.

Processo de Avaliação. Uma avaliação é realizada para avaliar um conjunto de processos selecionados de acordo com o(s) modelo(s) de avaliação escolhido(s). Seguindo a norma, o processo de avaliação conterá no mínimo as seguintes atividades:

1. Planejamento: deve ser desenvolvido um plano para a avaliação contendo informações, tais como as entradas iniciais requeridas, atividades, cronograma, recursos, entre outras.

2. Coleta de dados: para a coleta de dados devem ser utilizadas estratégias e técnicas explicitamente identificadas e que sejam demonstráveis. Deve ser estabelecida uma correspondência entre os processos da unidade organizacional e os elementos do modelo de avaliação de processos.

3. Validação dos dados: os dados coletados devem ser validados para confirmar se as evidências são objetivas, garantir que a evidência é suficiente e representativa e que os dados coletados, como um todo, sejam consistentes.

4. Pontuação de atributo de processo: com base nos dados validados deve ser atribuída uma nota para cada atributo de processo que formarão o perfil de processo para a unidade organizacional. O processo de tomada de decisão utilizado deve ser registrado, e deve ser mantida uma rastreabilidade entre a pontuação de um atributo e a evidência objetiva utilizada na pontuação do mesmo.

5. Comunicação dos resultados: os resultados da avaliação, incluindo no mínimo as saídas da mesma, devem ser registrados e entregues ao patrocinador da avaliação.

A ISO/IEC 15504 não define um método de avaliação, porém estabelece requisitos mínimos a serem empregados. Para uma avaliação a norma recomenda entradas iniciais, saídas, papéis e responsabilidades e o processo de avaliação mínimo.

\section{Requisitos para um Método de Avaliação de Processo de Software em Micro Empresas Associadas a Incubadoras}

Com base na pesquisa das características de micro empresas incubadas e incubadoras de 
base tecnológica [CONFEA 2004, MCT 2001] e na experiência de outras aplicações utilizando a ISO/IEC 15504 [Anacleto et al, 2004], identificamos os seguintes requisitos para um método de avaliação de processos de software de micro empresas incubada:

- O método deve visar à realização de uma avaliação com dois objetivos: 1) avaliação dos processos de software da empresa visando à melhoria destes processos e 2) acompanhamento por parte da incubadora dos atuais processos de software da empresa incubada; Como resultado deve ser provida uma descrição em alto-nível do processo de software da empresa e deverão ser identificados os pontos fortes e fracos e oportunidades de melhoria de acordo com o modelo de avaliação de processo.

- Ser baseado numa norma/modelo nacionalmente e internacionalmente reconhecido.

- A avaliação deve prover uma visão ampla sobre o processo de software como um todo (incluindo os processos técnicos, gerenciais, de fornecimento e de suporte) para obter uma primeira visão da situação atual ao invés de prover uma avaliação mais detalhada de alguns poucos processos.

- O modelo de avaliação e o método devem ser adaptados às características típicas de micro empresas recém formadas, considerando especificamente as seguintes características:

oProcesso de software informal e de baixa capacidade;

○Organização e comunicação simples;

○Poucos funcionários assumindo múltiplos papéis;

oEnfocando em poucos/um produto e/ou serviço da empresa;

○Projetos de curta duração com equipes pequenas;

- A avaliação deve ter um baixo custo, visando, por exemplo, que o esforço gasto em uma avaliação pelo avaliador não pode ser mais do 4 homens-hora, pois geralmente os recursos de um micro empresa recém formada são extremamente limitados. Também o esforço de representantes da empresa na avaliação deverá ser pequeno.

- Não exigir conhecimentos de engenharia de software por parte dos representantes da empresa que está sendo avaliada;

- Publicamente disponível em português, pois o método se direciona a empresas Brasileiras.

Considerando os requisitos identificados, se destacam os modelos/normas de avaliação de processo de software baseado em representações contínuas, como a norma ISO/IEC 15504 e o modelo CMMI-SW/continuous [SEI, 2004], que se mostraram mais flexíveis. Entretanto, considerando especificamente a sua aplicação em micro e pequenas empresas, quase não há métodos especificamente direcionados para este contexto com base no modelo CMMI-SW (apesar de existirem poucas diretrizes para aplicação do método SCAMPI em pequenas organizações). O modelo CMMI-SW também não inclui explicitamente processos voltados para a área de fornecimento, instalação e suporte, que se mostraram bastante importante no contexto de MPEs 
[Anacleto, Wangenheim e Salviano, 2004]. Conforme a norma ISO/IEC 15504 existem vários métodos de avaliação de processo de software adaptados para MPEs, incluindo, por exemplo, RAPID [Rout et al, 2000], SPINI [Mäkinen, Varkoi e Lepasaar, 2000], MARES [Anacleto, Wangenheim e Salviano, 2004]. Todos estes métodos são voltados a avaliações para melhoria de processo.

Uma abordagem freqüentemente aplicada em pequenas empresas de software com a finalidade de executar uma avaliação em alto nível em um dia de trabalho focalizando uma primeira visão em vez de avaliar em detalhe vários processos. Outros executam uma avaliação em conformidade com a ISO/IEC 15504 com um número pequeno de processos. Neste contexto, alguns destes métodos pré-definem um conjunto fixo de processos adaptado ao contexto de MPEs, como, por exemplo, RAPID (limitado a um conjunto de oito processos), ou permitem selecionar um conjunto de processos na correspondentes com as características de uma empresa, como, por exemplo SPINI [Mäkinen, Varkoi e Lepasaar, 2000] ou MARES [Anacleto, Wangenheim e Salviano, 2004]. Todos os métodos em conformidade ISO/IEC 15504 são, principalmente, baseados no Modelo de Referência de Processos como definido na ISO/IEC 15504-5. A estrutura da dimensão de capacidade é idêntica a ISO/IEC 15504-2 focalizando na maior parte em avaliações até o nível 3 . O processo da avaliação é baseado fortemente nos requisitos de execução de uma avaliação em conformidade definida na ISO/IEC 15504-2. Poucos métodos incluem uma etapa inicial anterior a avaliação real com o objetivo de caracterizar o contexto e guiar a seleção dos processos a serem investigados. Como resultados das avaliações, descobertas chaves, incluindo, os perfis de processos e pontos fortes e fracos e, opcionalmente, sugestões de melhoria, são relatados.

Entretanto, atualmente não há um método que seja direcionado especificamente para micro empresa associadas a uma incubadora de base tecnológica. Considerando esta situação, nós estamos adaptando o método MARES para este contexto com o objetivo de melhoria de processo de software das empresas e suportar $\mathrm{o}$ acompanhamento por parte da incubadora.

\section{Método MARES-MINI/EI}

Com base no método MARES - Metodologia de Avaliação de Processo de Software baseado na norma ISO/IEC 15504 [Anacleto, Wangenheim e Salviano, 2004], estamos desenvolvendo um método de avaliação - MARES-MINI/EI voltado especificamente para o contexto de micro empresas incubadas. O método de avaliação está sendo desenvolvido a partir de um estudo da literatura [Anacleto, Wangenheim e Salviano, 2004, ISO 2003, MCT 2001, SOFTEX 2004] e com base nas nossas experiências ganhas realizando avaliações de processo de software em MPEs [Anacleto et al, 2004].

O método MARES-MINI/EI visa avaliar a situação geral do processo de software de uma micro empresa incubada, identificando pontos fortes e fracos, riscos e oportunidades de melhoria com dois objetivos:

1. Suportar a melhoria de processo de software na empresa, e;

2. Suportar o acompanhamento e orientação pela incubadora à empresa associada.

De acordo com os requisitos identificados anteriormente, dentro deste contexto, o objetivo não é realizar uma avaliação detalhada de poucos processos em conformidade com a norma, mas prover uma visão geral do processo da empresa numa forma rápida e com baixo custo. Assim a avaliação é somente alinhada (e não completamente 
conforme) a norma ISO/IEC 15504 como um modelo internacionalmente reconhecido, que se mostrou flexível e customizável para o contexto de MPEs.

A seguir são descritos os principais componentes deste método, o Modelo de Avaliação de Processo e o Processo de Avaliação.

\subsection{Modelo de Avaliação de Processo}

De acordo com a norma ISO/IEC 15504, o modelo de avaliação proposto é composto por duas dimensões: dimensão de processo e dimensão de capacidade.

Dimensão de processo. De acordo com o objetivo da avaliação em identificar os pontos fortes e fracos no processo de software como um todo considerando as características típicas de micro empresas recém formadas, foi selecionado um subconjunto de 17 processos com base no modelo de referência de processos da ISO/IEC 15504-5 (vide Tabela 1). Os processos foram selecionados com base em experiências anteriores e analisando características comuns entre micro empresas [Anacleto et al 2004, MCT 2001].

\begin{tabular}{|c|c|}
\hline Grupo & Processos \\
\hline & Processos de Ciclo de Vida Primários \\
\hline \multirow{3}{*}{ Grupo de Fornecimento } & SPL.1 Fornecimento \\
\hline & SPL.2 Liberação de Software \\
\hline & SPL.3 Suporte à Aceitação de Software \\
\hline Grupo de Operação & OPE.2 Suporte ao Cliente \\
\hline \multirow[t]{8}{*}{ Grupo de Engenharia } & ENG.4 Análise de Requisitos de Software \\
\hline & ENG.5 Projeto (Design) de Software \\
\hline & ENG.6 Construção de Software \\
\hline & ENG.7 Integração de Software \\
\hline & ENG.8 Teste de Software \\
\hline & ENG.11 Instalação de Software \\
\hline & ENG.12 Manutenção de Software \\
\hline & Processos de Ciclo de Vida de Suporte \\
\hline \multirow[t]{4}{*}{ Grupo de Controle de Configuração } & CFG.1 Documentação \\
\hline & CFG.2 Gerência de Configuração \\
\hline & CFG.4 Gerência de Pedidos de Alteração \\
\hline & Processos de Ciclo de Vida Organizacionais \\
\hline \multirow[t]{3}{*}{ Grupo de Gerência } & MAN.3 Gerência de Projeto \\
\hline & MAN.4 Gerência de Qualidade \\
\hline & MAN.5 Gerência de Risco \\
\hline
\end{tabular}

Em geral, este conjunto de processos é considerado durante a avaliação. Entretanto, os processos que durante a avaliação se mostram irrelevantes, não são avaliados. Por exemplo, se uma empresa ainda não chegou no estágio de prestar suporte, este processo não é analisado. Caso haja necessidade, outros processos podem ser adicionados de acordo com as necessidades de uma empresa específica, baseados, por exemplo, na ISO/IEC 15504-5.

Durante a avaliação é observado, principalmente, se e como os processos são executados e que produtos são utilizados/gerados. Assim, para este conjunto de processos foram definidos, com base na ISO/IEC 15504-5, práticas bases e produtos gerados/utilizados tipicamente relevantes no contexto de micro empresas recém formadas. 
Dimensão de capacidade. Como geralmente o processo de software de micro empresas recém formadas se encontra em um nível baixo de capacidade, neste modelo somente são considerados os níveis de capacidade 0 e 1 (tabela 2) de acordo com a norma ISO/IEC 15504-2.

Tabela 2: Níveis de capacidade da ISO/IEC 15504

\begin{tabular}{|l|l|}
\hline Nível de Capacidade & Características do Nível \\
\hline Nível 0 (Incompleto) & $\begin{array}{l}\text { O processo não está implementado, ou falha para atingir seu propósito. Neste } \\
\text { nível há pouco ou nenhuma evidência de qualquer atingimento sistemático do } \\
\text { propósito do processo. }\end{array}$ \\
\hline Nível 1 (Executado) & $\begin{array}{l}\text { O propósito do processo é geralmente alcançado, mas isto talvez não seja } \\
\text { rigorosamente planejado e acompanhado. As pessoas da empresa reconhecem } \\
\text { que uma ação deve ser executada, e quando deve ser executada. Também } \\
\text { existem produtos de trabalho para o processo e estes evidenciam a satisfação do } \\
\text { propósito do processo. }\end{array}$ \\
\hline
\end{tabular}

Assim, o principal enfoque da avaliação é analisar se os processos relevantes são executados de acordo com o modelo de referência com base na ISO/IEC 15504-5. Caso haja necessidade, outros níveis de capacidade podem ser considerados com base na ISO/IEC 15504-2.

\subsection{Processo de Avaliação}

Considerando os requisitos levantados anteriormente, nós propomos um processo simplificado de avaliação baseado na ISO/IEC 15504 alinhado às características específicas das micro empresas incubadas e ao objetivo desta avaliação. Desta maneira, os processos selecionados pelo método podem ser observados na empresa como um todo de uma forma rápida e em alto-nível.

Uma avaliação realizada com base na metodologia MARES-MINI/EI é uma avaliação independente, realizada por um avaliador externo à empresa avaliada, com a participação de representantes da empresa. Os principais papéis envolvidos na avaliação são:

- Avaliador: Pessoa competente para realizar avaliações utilizando o método e responsável pela realização de todas as atividades da avaliação. Geralmente, a avaliação pode ser feita por um avaliador.

- Representante da Incubadora: Pessoa representando a Incubadora, por exemplo, o diretor da incubadora ou pessoal responsável para o acompanhamento das empresas associadas. Geralmente este representante também é o patrocinador da avaliação.

- Participantes(s) da empresa: Pessoas da empresa que estão envolvidas nos processos a serem avaliados que são convidadas a participar da avaliação. É responsabilidade da equipe da empresa informar dados corretos para que a avaliação tenha resultados mais significativos para a organização.

- Representante da empresa: Uma pessoa representando a empresa (geralmente um do(s) sócio(s) da empresa). O representante da empresa é o ponto de contato e coordena as atividades da avaliação pelo lado da empresa.

A seguir são descritas as partes principais atividades que compõem o processo proposto: Planejamento, Caracterização, Coleta de dados, Análise e Pontuação, Validação e Apresentação dos resultados e Controle e Finalização. 
Planejamento. A avaliação se inicia com o planejamento, que envolve um contato inicial com o patrocinador da avaliação (geralmente responsável da incubadora) e o(s) diretor (es) da empresa a ser avaliada. Através deste contato são definidos: um representante da empresa, o cronograma, o avaliador e o(s) participante(s) da empresa. Também são assinados uma especificação de serviço e um termo de confidencialidade pelo patrocinador, pelo representante da empresa e pelo avaliador.

Caracterização. No início da avaliação são levantadas informações gerais sobre a empresa em que a avaliação é realizada, por exemplo, número de funcionários, dados sobre seu produto/projetos, a(s) sua(s) meta(s) de negócio e de melhoria. Para isto pode ser utilizado um questionário de caracterização a ser preenchido pelo representante da empresa antes da execução da avaliação.

Coleta de dados. Os dados necessários para a avaliação são coletados em uma entrevista com participantes da empresa. Nesta entrevista, são revisadas e completadas as informações levantadas no questionário de caracterização. Isto permite ao avaliador o melhor entendimento do contexto e também do principal produto da empresa, além de discutir suas metas de negócio, problemas já conhecidos, etc.

Em seguida, são coletados dados referentes às práticas bases e produtos utilizados/gerados nos processos considerados no modelo de avaliação. Esta coleta pode ser estruturada e documentada utilizando um Formulário da Entrevista (vide Figura 2). O formulário consta no cabeçalho o nome dos entrevistados e os seus papéis dentro da empresa, além de identificar a(s) meta(s) de negócio, aspecto(s) importante(s) de qualidade e o estágio de crescimento. A principal parte do formulário contém os processos selecionados, juntamente com suas práticas bases e produtos de trabalho. Durante a avaliação, comentários às práticas bases/produtos de trabalhos podem ser anotadas e/ou o atendimento de práticas bases pode ser identificado usando as categorias:

- $\quad \mathrm{N}$ - Não atingido: Não existe evidência do alcance da prática base definida no processo avaliado.

- P - Parcialmente atingido: Existe alguma evidência de aproximação e algum alcance da prática base definida no processo avaliado.

- L - Largamente atingido: Existe evidência de aproximação sistemática à prática base definida e de alcance significativo do processo avaliado.

- F - Completamente atingido (Fully): Existe evidência de uma aproximação completa e sistemática à prática base definida e de total alcance da prática base definida no processo avaliado.

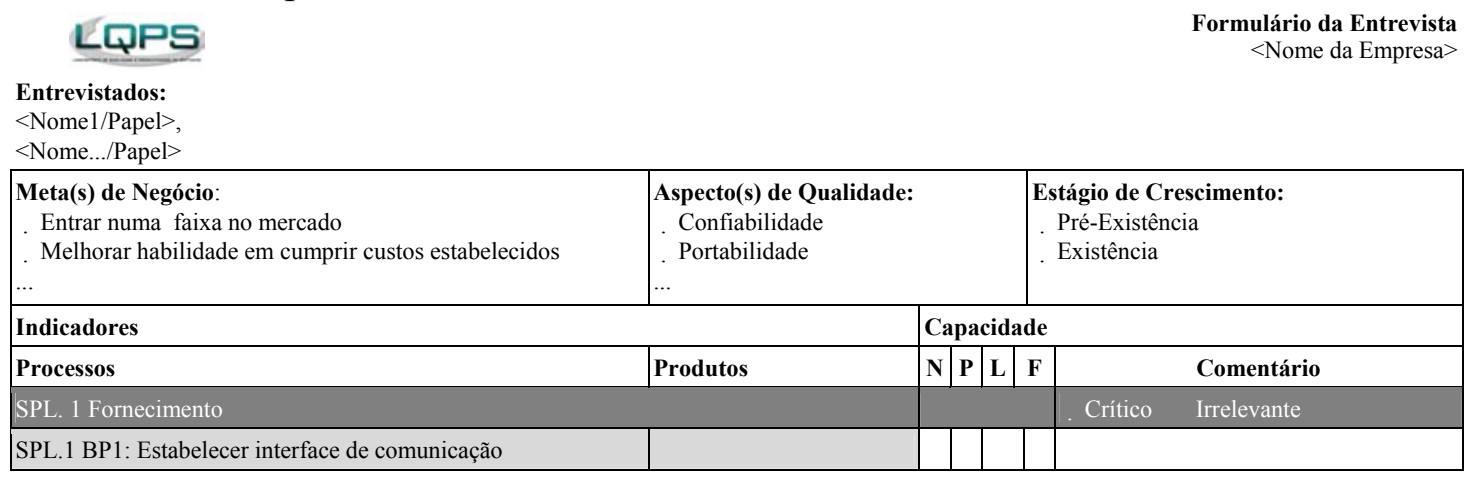




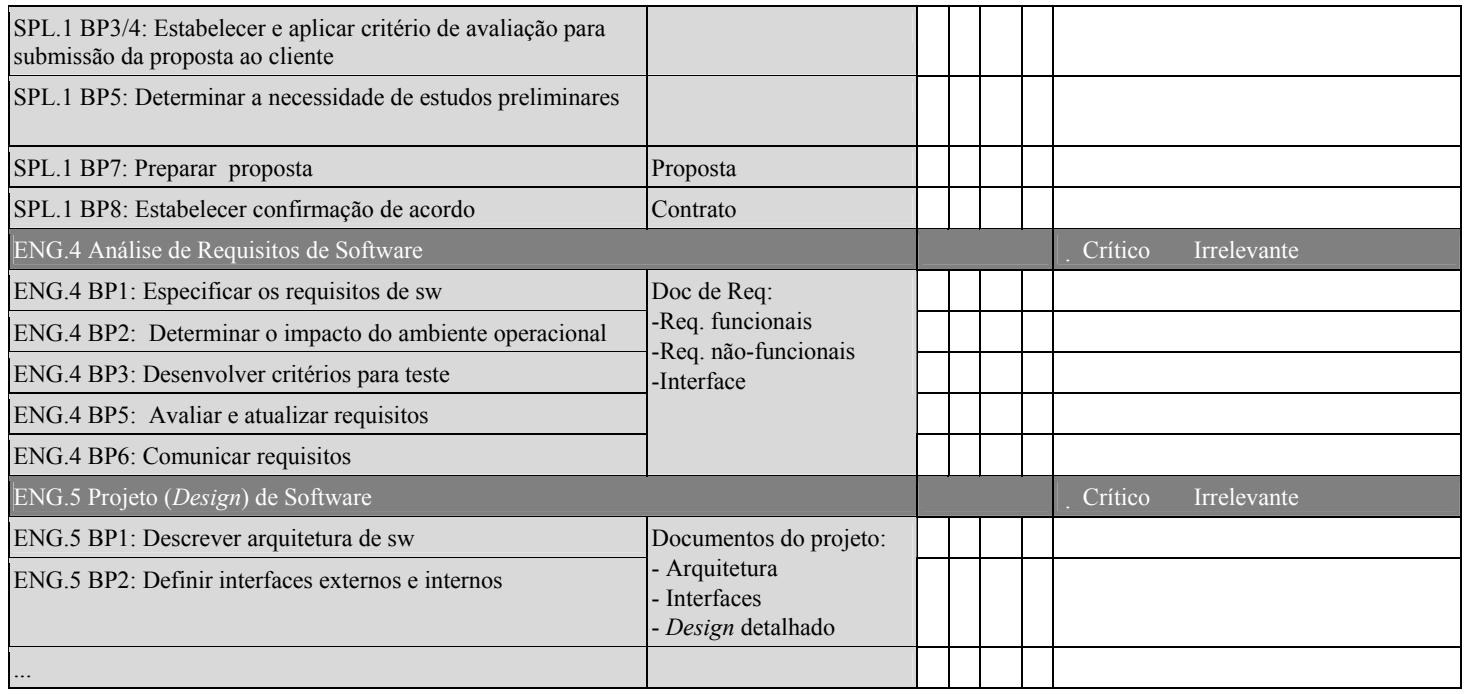

Figura 2: Extrato do Formulário de Entrevista

Processos que são identificados como críticos em relação ao atendimento da(s) meta(s) de negócio podem ser marcados no formulário. Processos que se mostraram irrelevantes no contexto de uma empresa específica, não são mais considerados durante a entrevista.

Análise e Pontuação. Com base nos dados coletados por meio do questionário de caracterização e durante a entrevista, é analisado o processo de software da empresa pelo avaliador experiente. Em um primeiro passo é documentado em alto nível se e como são executados os processos relevantes na empresa, resultando numa descrição alto-nível do processo de software. Num segundo passo, cada processo relevante é pontuado de acordo com o atendimento das práticas bases que estão relacionadas. Como no método MARES-MINI/EI estamos somente considerando os níveis 0 e 1 de capacidade de processo, somente um Atributo de Processo "PA1.1 Atributo de execução de processo" está sendo avaliado de acordo com a norma ISO/IEC 15504. Assim, com base no grau de atendimento das práticas bases referentes a um processo este atributo de processo está sendo pontuado:
$\mathbf{N}$ não atingido
$\mathbf{P}$ parcialmente atingido
L largamente atingido
F completamente atingido

0 a $15 \%$ atingido

$15 \%$ a $50 \%$ atingido

$50 \%$ a $85 \%$ atingido

$85 \%$ a $100 \%$ atingido

$\mathrm{O}$ atingimento é determinado pelo avaliador experiente com base nos dados coletados. Seguindo a norma ISO/IEC 15504 para atingir o nível 1 de capacidade referente a um processo, o atributo de processo PA1.1 precisa ser atingido largamente ou completamente. Assim, o nível de capacidade é determinado para todos os processos avaliados. Os processos que se mostraram não relevantes no contexto da empresa no momento da avaliação, não são avaliados (indicado com n/a). Outros processos que não foram avaliados ou para quais não foram coletados dados suficiente são marcados com um X. Como resultado desta análise são gerados perfis de processo indicando o nível de capacidade (vide Figura 3). Para mostrar detalhes do atingimento do nível de capacidade, também o grau de atendimento do atributo de processo PA1. 1 é mostrado. 


\begin{tabular}{|c|c|c|c|c|}
\hline \multirow{3}{*}{$\begin{array}{r}n / c \\
\text { PROCESSOS }\end{array}$} & \multicolumn{3}{|c|}{ Níveis de Capacidade } & dade \\
\hline & \multicolumn{2}{|l|}{$\mathbf{0}$} & \multicolumn{2}{|l|}{1} \\
\hline & $\mathbf{N}$ & $\mathbf{P}$ & L & $\mathbf{F}$ \\
\hline SPL.1 Fornecimento & & & & \\
\hline SPL.2 Liberação de Software & & & & \\
\hline SPL.3 Suporte à Aceitação de Software & & & & \\
\hline ENG.4 Análise de Requisitos de Software & & & & \\
\hline ENG.5 Projeto (Design) de Software & & & & \\
\hline ENG.6 Construção de Software & & & & \\
\hline ENG.7 Integração de Software & \multicolumn{4}{|l|}{$\mathrm{n} / \mathrm{a}$} \\
\hline ENG.8 Teste de Software & & & & \\
\hline ENG.11 Instalação de Software & & & & \\
\hline ENG.12 Manutenção de Software & \multicolumn{4}{|l|}{$\mathrm{n} / \mathrm{a}$} \\
\hline OPE.2 Suporte ao Cliente & \multicolumn{4}{|l|}{$\mathrm{n} / \mathrm{a}$} \\
\hline MAN.3 Gerência de Projeto & & & & \\
\hline MAN.4 Gerência de Qualidade & & & & \\
\hline MAN.5 Gerência de Risco & & & & \\
\hline CFG.1 Documentação & & & & \\
\hline CFG.2 Gerência de Configuração & & & & \\
\hline CFG.4 Gerência de Pedidos de Alteração & \multicolumn{4}{|l|}{$\mathrm{n} / \mathrm{a}$} \\
\hline
\end{tabular}

Figura 3: Exemplo de perfis de processo

Com base nestes resultados, são identificados os principais pontos fortes e fracos observados no processo de software da empresa, indicando as oportunidades para melhoria.

Isto é feito com base no modelo de referência de processos considerando o alvo de atingir o nível 1 de capacidade em todos os processos relevantes.

Validação e Apresentação dos resultados. Em seguida, os resultados da análise são apresentados para os participantes da empresa. Neste momento as observações feitas que resultaram nestes resultados da avaliação também podem ser validadas pelos participantes da empresa. Especialmente os pontos fortes e fracos são brevemente discutidos para ajudar no direcionamento de ações de melhoria.Todos estes resultados são documentados em um relatório que é entregue para o representante da empresa e para o representante da Incubadora.

Controle e finalização. A execução da avaliação é monitorada e controlada, principalmente, em termos de esforço e duração/prazos. No intuito de melhorar continuamente o método são analisadas as experiências ganhas na aplicação do método suportado pelo uso de questionários de satisfação obtendo feedback da empresa que foi avaliada, da incubadora e do avaliador.

O método que está sendo desenvolvido define detalhadamente o processo de avaliação incluindo templates para documentos sendo usados ou gerados durante a avaliação [Pickler, Wangenheim e Salviano, 2005]. Também está sendo desenvolvida uma ferramenta de software com base no método para facilitar a sua aplicação deste método na prática.

\section{Primeiras Experiências}

O método está sendo desenvolvido com base na literatura [Anacleto, Wangenheim e Salviano, 2004, ISO 2003, MCT 2001, SOFTEX 2004] e nas nossas experiências aplicando a ISO/IEC 15504 em micro e pequenas empresas de software [Anacleto et.al, 2004]. Começando agora a validação do método que está sendo desenvolvido, nós ganhamos as primeiras experiências aplicando o método em uma micro empresa recém formada associada à Incubadora Centro GeNESS em Florianópolis/SC. 
Esta empresa iniciou suas atividades em dezembro 2003 e atualmente inclui 4 sócios. Sua especialização é a criação, a comercialização e a implantação de soluções tecnológicas, que atendam as necessidades e as expectativas das empresas do ramo moveleiro. A empresa atualmente está em fase de aperfeiçoamento do principal produto o que é feito em cooperação com um cliente do setor alvo. A empresa ainda não começou a venda efetiva do produto e conseqüentemente ainda não presta suporte. A empresa se encontra no segundo ano de incubação no Centro GeNESS.

A avaliação foi patrocinada pela Incubadora Centro GeNESS no contexto do projeto de pesquisa 15504MPE. A avaliação foi realizada seguindo o método MARESMINI/EI como descrito no capítulo anterior. A equipe de avaliação foi composta por dois avaliadores. A presença de um segundo avaliador neste caso foi necessária para também permitir a discussão/revisão do próprio método entre os avaliadores. Participaram também 2 sócios da empresa e a incubadora foi representada por seu diretor.

\begin{tabular}{|c|c|c|c|c|c|c|c|c|}
\hline \multirow[t]{2}{*}{ Atividade } & \multicolumn{8}{|l|}{ DIA } \\
\hline & $05 / 12 / 2004$ & $06 / 12 / 2004$ & 07/12/2004 & $08 / 12 / 2004$ & $09 / 12 / 2004$ & $10 / 12 / 2004$ & $17 / 12 / 2004$ & $20 / 12 / 2004$ \\
\hline \multicolumn{9}{|l|}{ Planejamento } \\
\hline \multicolumn{9}{|l|}{ Caracterização } \\
\hline \multicolumn{9}{|l|}{ Coleta de dados } \\
\hline \multicolumn{9}{|l|}{ Análise e Pontuação } \\
\hline \multicolumn{9}{|l|}{$\begin{array}{l}\text { Validação e apresentação } \\
\text { dos resultados }\end{array}$} \\
\hline Controle e finalização & & & & & & & & \\
\hline
\end{tabular}

Figura 4: Tempo gasto para cada atividade da avaliação.

A presente experiência foi realizada durante um período total de oito dias (com exceção do contato inicial e dos questionários). Isto se dá ao fato deste tipo de avaliação não ter sido anteriormente feita e de ainda não haver templates prontos para a realização da avaliação. Por este motivo, foi necessário reservar um maior tempo para uma análise mais detalhada. Porém, espera-se que depois que o método for concluído, avaliações deste tipo sejam realizadas em apenas um único dia.

Os custos da avaliação são, basicamente, homens-hora de trabalho pessoal. $\mathrm{Na}$ tabela 3 mostramos o esforço gasto separado por avaliador, participantes/representante da empresa e representante da incubadora. Também estamos separando o esforço por número de avaliador e participantes/representante da empresa, pois o esforço depende diretamente do número de avaliadores e participantes, e no caso dos avaliadores, estamos prevendo no somente a participação de um único avaliador após o término do desenvolvimento do método.

Assim, podemos observar, que nesta primeira experiência, o esforço total por um avaliador foi de 5:25 homens-hora, o que é considerado adequado, mas considerando a nossa meta pretendemos melhorar ainda o método para poder reduzir este esforço no final para até 4 homens-hora. Por exemplo, por meio da disponibilidade de templates dos documentos e uma ferramenta de software.

Analisando o esforço gasto por parte da empresa, este valor também é considerado ainda alto com quase 5 homens-hora/por participante. Isto em partes é devido ao alto esforço de 2 horas levadas para o preenchimento do questionário na atividade de caracterização. Desta forma, para melhorar o método está sendo revisado este questionário de caracterização. 
Assim, o esforço total dos avaliadores, dos representantes da empresa e da incubadora que foi gasto na avaliação foi de aproximadamente 20:10 homens-hora (veja tabela 3).

Tabela 3: Esforço gasto durante a avaliação (em homens-hora)

\begin{tabular}{|c|c|c|c|c|c|c|}
\hline Atividades & $\begin{array}{c}\text { Por } \\
\text { avaliador }\end{array}$ & $\begin{array}{c}\text { Total de } \\
\text { avaliadores } \\
(* 2)\end{array}$ & $\begin{array}{c}\text { Por } \\
\text { participante/ } \\
\text { Representante } \\
\text { da empresa }\end{array}$ & $\begin{array}{c}\text { Total de } \\
\text { participantes/ } \\
\text { representante } \\
(* 2)\end{array}$ & $\begin{array}{c}\text { Representante } \\
\text { da } \\
\text { Incubadora } \\
(* 1)\end{array}$ & TOTAL \\
\hline Planejamento & $0: 15$ & $2 * 0: 15$ & $0: 30$ & $2 * 0: 30$ & $1 * 0: 30$ & 2:00 \\
\hline Caracterização & $0: 30$ & $2 * 0: 30$ & $2: 00$ & $1 * 2: 00^{1}$ & $1 * 0: 00$ & 3:00 \\
\hline Coleta de dados & $1: 10$ & $2 * 1: 10$ & $1: 10$ & $2 * 1: 10$ & $1 * 0: 00$ & $4: 40$ \\
\hline Análise e Pontuação & $2: 00$ & $2 * 2: 00$ & 0:00 & $2 * 0: 00$ & $1 * 0: 00$ & $4: 00$ \\
\hline $\begin{array}{c}\text { Validação } e \\
\text { Apresentação dos } \\
\text { resultados }\end{array}$ & $1: 00$ & $2 * 1: 00$ & $1: 00$ & $2 * 1: 00$ & $1 * 0: 30$ & $4: 30$ \\
\hline $\begin{array}{c}\text { Controle e } \\
\text { Finalização }\end{array}$ & $0: 30$ & $2 * 0: 30$ & $0: 15$ & $2 * 0: 15$ & $1 * 0: 30$ & $2: 00$ \\
\hline TOTAL & $5: 25$ & $10: 50$ & $4: 55$ & $7: 50$ & $1: 30$ & $20: 10$ \\
\hline
\end{tabular}

Em geral, a distribuição do esforço entre a equipe de avaliação (de aproximadamente $46 \%$ ) e os representantes da empresa (41\%), e o representante da incubadora (13\%) é considerado adequado para este tipo de avaliação.

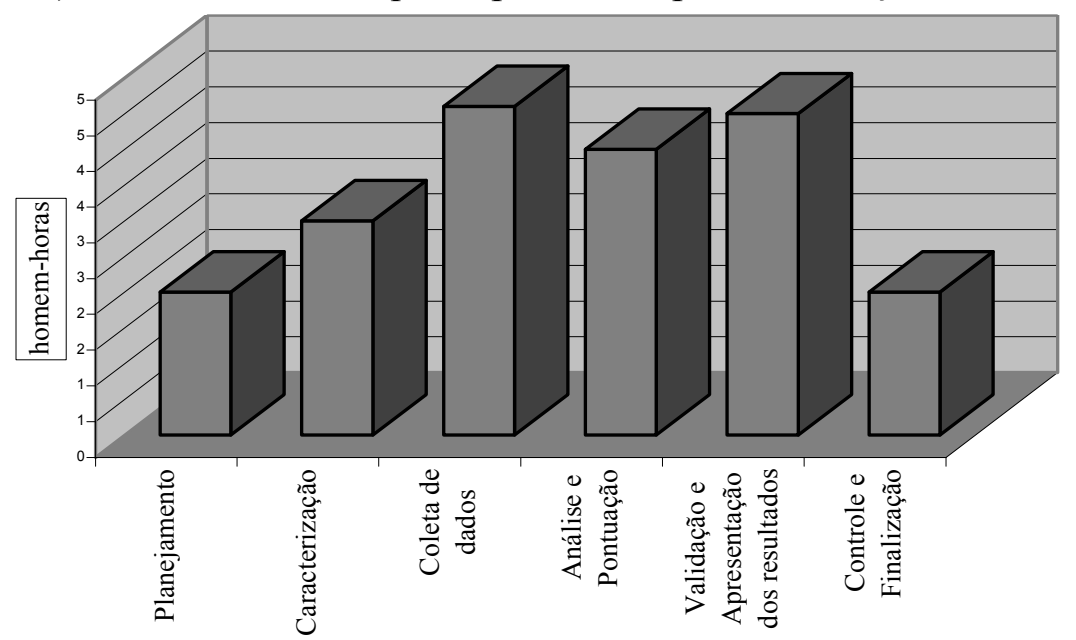

Figura 5. Distribuição do esforço total gasto por atividade da avaliação.

A respeito das atividades individuais durante a avaliação (veja figura 5), foi observado que a maior parte do esforço foi gasto nas atividades de coleta de dados e de validação e apresentação dos resultados, principalmente como este esforço diretamente depende do número de pessoas participantes (tanto da parte dos avaliadores quanto dos participantes da empresa). Por um lado, com uma maior participação de integrantes da empresa o esforço aumenta, porém, nós observamos também que no outro lado isto pode ajudar a motivar e incentivar uma primeira discussão dos resultados da avaliação e das ações da melhoria.

No geral, tanto os representantes da empresa quanto da incubadora consideraram a avaliação como um grande benefício. Para a incubadora houve uma ajuda na

\footnotetext{
${ }^{1} \mathrm{O}$ esforço por parte da empresa na atividade de caracterização não foi multiplicado por 2 devido ao fato de que apenas o representante da empresa participou do preenchimento do questionário de caracterização.
} 


\section{Simpósio Brasileiro de Qualidade de Software}

identificação de pontos fracos na área técnica da empresa associada importante para direcionar a estratégia de acompanhamento e um suporte mais adequado para a empresa associada. O resultado da avaliação é considerado um meio importante e complementar além de dados e informações gerenciais que a incubadora levanta para acompanhar o progresso da empresa mais voltado na área de negócio e administração.

Para a própria empresa a avaliação também ajudou a ter uma visão geral da atual situação de seu processo de software. A descrição alto-nível do processo de software como resultado da avaliação foi aprovada pelos participantes da empresa. E como um dos resultados da avaliação, as sugestões de melhoria também foram bem compreendidas e aceitas tanto pela empresa quanto pela incubadora. Em geral, a avaliação auxiliou para estruturar o processo de software e identificar os principais pontos a serem melhorados e na priorização destas ações considerando o contexto da empresa e as suas metas de negócio.

\section{Lições Aprendidas}

Esta experiência provê uma primeira indicação que o método MARES-MINI/EI pode ser adequado para avaliar o processo de software em alto nível com custo razoável em empresas incubadas recém formadas. Especificamente o processo de coleta de dados e análise se mostrou adequado para este contexto. O formulário de entrevista se mostrou útil facilitando uma entrevista estruturada e eficiente. $\mathrm{O}$ modelo de avaliação também neste caso foi confirmado adequado para este tipo de empresa.

Porém observamos também alguns pontos fracos a serem melhorados especialmente voltados ao objetivo de reduzir o esforço e conseqüentemente reduzir o custo. Estas ações de melhoria incluem:

- Revisão e melhoria do questionário de caracterização;

- Elaboração de templates para todos os documentos serem utilizados e/ou gerados durante a avaliação.

- Criação de um modelo que explicitamente relaciona aspectos de contexto, processos e riscos e oportunidades de melhoria com base em melhores dados práticos disponível na literatura e com base nas nossas experiências;

- Desenvolvimento de uma ferramenta de software suportando a aplicação do método

- Integração com os outros modelos/normas como, por exemplo, CMMI-SW [SEI, 2004] e mps-BR [MPS, 2005], em paralelo.

\section{Conclusão}

Neste artigo apresentamos uma proposta para um método de avaliação de processo de software customizado para micro empresas incubadas. O método descreve um modelo de avaliação de processo de software e um processo simples de avaliação baseado na norma ISO/IEC 15504 adaptados às características típicas de micro empresas incubadas. Primeiras experiências indicam que o método pode ser adequado para avaliar o processo de software numa forma alto-nível com baixo custo considerando as características típicas de micro empresas incubadas. Com base nestas experiências, o método está sendo evoluído e uma ferramenta de suporte está sendo implementada. Também são planejadas futuras aplicações para continuar a validação do método. 


\section{Agradecimentos}

Os autores gostariam agradecer aos órgãos financiadores que viabilizaram a execução deste projeto incluindo o CNPq, FUNCITEC, UNIVALI e CenPRA. Também agradecer aos representantes das empresas participantes, pela sua participação e compartilhamento das informações e ao Centro GeNESS, parceiro na execução no projeto 15504MPE.

\section{Referências}

Anacleto, A., Gresse von Wangenheim, C. e Salviano, C. F. Avaliação de Processos para Início de Programas de Melhoria em Micro e Pequenas Empresas de Software. SIMPROS, Novembro, 2004.

Anacleto, et al. Experiences Gained from Applying ISO/IEC 15504 to Small Software Companies in Brazil. Proceedings of SPICE Conference, Portugal, 2004.

Associação Brasileira de Normas Técnicas. Série ISO 9000:2000: Sistemas de Gestão da Qualidade. ABNT, 2001.

Conselho Federal de Engenharia, Arquitetura e Agronomia (CONFEA). Disponível em: http://www.confea.org.br/revista/materias/edicao_14/materia_08/materia.asp.

Acessado em 30 de agosto de 2004.

International Organization for Standardization. ISO/IEC 12207 Amd 1/2: 2002: Information technology - Software life cycle processes. ISO/IEC International Standard, 2002.

International Organization for Standardization. ISO/IEC 15504: Information Technology - Process Assessment, Part 1 to Part 5, ISO/IEC International Standard, 2003-2005 (em desenvolvimento).

Mäkinen, T., Varkoi, T. e Lepasaar, M. A Detailed Process Assessment Method For Software SMEs. Proceedings of the EuroSPI 2000 Conference, 2000.

Ministério de Ciência e Tecnologia. Pesquisa Nacional de Qualidade e Produtividade no Setor de Software Brasileiro, Brasil, 1999/2001.

Melhoria de Processo do Software Brasileiro - MPS-BR Disponível em: http://www.softex.br/cgi/cgilua.exe/sys/start.htm?sid=191. Acessado em: $01 \mathrm{de}$ março de 2005.

Pickler, K.K; Gresse von Wangenheim, C., Salviano, C. F. MARES-MINI/EI: Método de Avaliação para Determinação da Capacidade dos Processos em Micro Empresas Incubadas. Relatório Técnico LQPS001.05P, Laboratório de Qualidade e Produtividade de Software, UNIVALI, São José, 2005.

Rout, et al. The RAPID Assessment of Software Process Capability”, SPICE 2000.

Sociedade Brasileira para Promoção da Exportação de Software (Sociedade SOFTEX) Centro SOFTEX GENESIS e sub-núcleo regional SOFTEX. Disponível em: http://www.ibt.org.br/softex.htm. Acessado em: 15 de setembro de 2004.

Software Engineering Institute. CMMI (Capability Maturity Model Integration). http://www.sei.cmu.edu/cmmi. Acessado em: 25 de setembro de 2004.

The SPICE Trials. Disponível em: http://www.sqi.gu.edu.au/spice/trials/. Acessado em: 01 de março de 2005. 